\title{
CICLO DE VIDA, ESTRUTURAS REPRODUTIVAS E DISPERSÃO DE POPULAÇÕES EXPERIMENTAIS DE CAPIM-CARRAPICHO (Cenchrus echinatus L.)
}

\author{
R.P. DE B. PACHECO* \& G. DE MARINIS** \\ * Professor Assistente - Departamento de \\ Botânica, Instituto de Biociências, Letras e \\ Ciências Exatas - UNESP. 15.100-São \\ José do Rio Preto, SP. \\ ** Professor Titular - Departamento de Botâ - \\ nica, Instituto de Biociências - UNESP. \\ 13.500 - Rio Claro, SP.
}

\section{RESUMO}

A partir de semeaduras mensais de 500 cariopses em áreas de 5,00 x $3,80 \mathrm{~m}$ em sulcos distanciados de um metro e com profundidade de $3 \mathrm{~cm}$ foram obtidas 12 populações experimentais. Após 20 dias foram feitos desbastes nos canteiros restando 120 plantas distanciadas de $20 \mathrm{~cm}$ nas linhas. A cada mês foram coletadas ao acaso, 10 plantas para a contagem das estruturas reprodutivas.

Considerando-se as quantidades de racemos, de fascículos e de cariopses, épocas de florescimento, tempo de dispersão e duração do ciclo de vida foi possível distinguir quatro periodos de semeadura. $\mathrm{O}$ primeiro de novembro a janeiro caracterizado pela quantidade de racemos e de fascículos bem maior que a dos outros períodos, cerca de $70 \%$ do total geral e também pela maior quantidade de cariopses. O início do florescimento foi o mais precoce $\left(2 .^{\circ}\right.$ mês) a dispersão de fascículos durante 120 dias com os maiores ID $(72 \%)$ e 210 dias de duração do ciclo de vida. O segundo de fevereiro a março caracterizado pela menor quantidade de race-mos, de fascículos e de cariopses $(2 \%$ do total geral). O início do florescimento foi tardio (4. ${ }^{\circ}$ mês); dispersão de fascículos durante 60 dias e o menor ID (44\%); 180 e 150 dias, respectivamente, de duração do ciclo de vida. O $3 .^{\circ}$ período de abril a julho, caracterizado por quantidade pequena de racemos $(19 \%$ do total geral) e quantidade intermediária de fascículos e cariopses (cerca de $21 \%$ do total geral). O início do florescimento foi tardio (4. ${ }^{\circ}$ mês); dispersão de fascículos durante 60 dias (para as de abril) e 90 dias (para as de maio, junho e julho), ID (70\%) e 210 dias de duração do ciclo de vida.

$04 .^{\circ}$ período de agosto a outubro, caracterizado por quantidade muito pequena de race-mos, de fascículos e de cariopses (7\% do total geral). 0 início do florescimento ocorreu no 3. ${ }^{\circ}$ mês; dispersão de fascículos durante 60 dias, ID (47\%) e 150 dias (agosto) e 120 dias (setembro e outubro) de duração do ciclo.
Palav ras-ch ave: Capim-carrapicho, ciclo de vida, estruturas reprodutivas, dispersão.

\section{SUMMARY}

LIFE CYCLE, REPRODUCTIVE STRUCTURES AND DISPERSION OF EXPERIMENTAL POPULATIONS OF SANDBUR (Cenchrus echinatus L.)

Twelve experimental populations were obtained by making monthly sowings in $3 \mathrm{~cm}$ deep depressions spaced one meter apart in $5,00 \times 3,80 \mathrm{~m}$ plots. After 20 days the plots were thi nned to leave 120 plants $20 \mathrm{~cm}$ apart. Each month 10 plants were randomly harvested and the reproductive structures counted.

Four sowing periods were distinguishable based on the number of racemes, fascicles and caryopses produced, the time of initiation of flowering, duration of fascicle dispersal and life cycle len gth. The first pe riod includes sowings made in the months of november to january and is characterized by the highest production of racemes and fascicles, about $70 \%$ of the total, as well as the greatest production of caryopses. Also, the initiation of flowering was the most precocious ( $2^{\text {nd }}$ month), the pethe dispersal index the highest $(72 \%)$ and the life cycle long (210 days). The second period includes sowings made in February and March and is characterized by the lowest production of racemes, fascicles and caryopses (2\% of the to tal). In it iation of flowering was late (4 th month). Fascicle dispersal ocurred during 60 days and the dispersal index was the lowest observed (44\%). Life cycle length was 180 and 150 days respectively for the January and $\mathrm{Fe}$ bruary sowings. The third period includes April to June and was characterized by low raceme production (19\% of the total) and intermediate production of fascicles and caryopses (about $21 \%$ of the total). The initiation of flowering riod of fascicle dispersal the longest (210 days), 
was retarded ( $4^{\text {th }}$ month), fascicle dispersal lasted 60 days for the April sowing and 90 days for the sowings of May, June and July. The dispersal index was $70 \%$ and life cycle length was 210 days. The fourth period, sowings of August and October, was characterized by very low production of racemes, fascicles and caryopses (7\% of the total). Flowering was initiation in the third month and fascicle dispersal ocurred during 60 days. The dispersal index was $47 \%$ and life cycle length 150 (August sowing) and 120 (September and October sowings) days.

Keywords: sandbur, life cycle, reproductives, structures, dispersion.

\section{INTRODUÇÃO}

O capim-carrapicho é uma planta herbácea, considerada como muito abundante e altamente nociva, tendo sido classificada entre as seis gramíne as de ciclo anual mais prejudiciais no Brasil (2). Holm et al. (8) citam Cenchrus echinatus $\mathbf{L}$. como infestante num total de 18 culturas em 35 países. No Brasil é citada por muitos autores $(1,2,3,4,6,8,9,13)$, como inf estante nas cul turas de alg odão, ma mona, amendoim, citros, feijã̃o, mandioca, soja, cana-de-açúcar, menta, cebola e tomate, como também nas pastagens. Felippe et al. (7) verificaram que à temperatura constante de 25 . $^{\circ} \mathrm{C}$, o esc uro acelera a germinação, mas não altera $\mathrm{o}$ número final de sementes germinadas. Deuber et al. (5) verificaram que a profundidade máxima de germi nação foi de $11,0 \mathrm{~cm}$ em vasos, de $9,0 \mathrm{~cm}$ em solo argiloso e de 10,0 cm em solo barrento e, em condições de campo observaram frequente germinação de duas ou mais car ${ }^{i 0}$ pses por fascículo.

Pacheco (12) verificou que em uma amostra de 500 fascículos coletad os do solo, todos possuíam pelo menos uma cariopse e que todas as plantas já completamente secas apresentavam somente fascículos estéreis. $\mathrm{O}$ capim-carrapicho apresenta-se em condições de dispersão durante todos os meses do ano (10) com capacidade reprodutiva aparente muito maior na época quente e úmida, sendo portanto, uma espécie de dispersão predominantemente estival (11).

Com o objetivo de conhecer o seu ciclo de vida ao longo do ano, a sua produtividade em estruturas reprodutivas e fornecer subsídios para o seu controle, foram instaladas 12 populações experimentais de capim-carrapicho no campo da Seção Fauna-Flora Experimental do Instituto de Planejamento e Estudos Ambientais de Presidente Prudente UNESP.

\section{MATERIAIS E MÉTODOS}

A semeadura mensal de 500 cariopses foi realizada em parcelas de $5,00 \mathrm{~m} \mathrm{x}$ $3,80 \mathrm{~m}$, em sulcos de cerca de $3 \mathrm{~cm}$ de profundidade, no espaçamento de um metro. O plantio foi feito após a chuva ou, quando não, após umidecimento do terren o através de regadores. A pós 20 dias da semeadura foi feito o desbaste, deixando 20 plantinhas em cada sulco a in tervalos de $20 \mathrm{~cm}$ num total de 120 plantas por parcela. A cada mês foi coletada ao acaso uma amostra de 10 plantas com razoável quantidade de solo e coloca das sobre peneira, sob esguicho de água, tentando-se evitar perda de material. Em seguida as plantas for am lavadas em água de torneira e deixadas sobre papel absorvente no laboratório. A idade da planta foi estimada a partir do dia da semeadura e o ciclo foi considerado completo quando a planta se apresentava completamente seca e com seus racemos nus de fascículos maduros.

O número de fascículos dispersados dos racemos incompletos (FdRi) foi estimado a partir da média de fascículos dos racemos completos ( XFRc ), obtida para cada mês de idade. O resultado obtido da subtração da média de fascículos dos racemos completos ( XFRc) e da média de fascículos dos racemos incompletos ( XFRi ), multipli cado pelo número de Ri foi considerado como número de fas cículos dispersad os a partir dos Ri. Esta estimativa pode ser, resu midamen te demonstrada na equação : FdRi = (XFRi) - XFRi) Ri ora proposta. De modo semelhante, o número de fascículos dispersados dos racemos nus (FdRn) foi estimado a partir da média de fascí- 
culos dos racemos completos ( XFRc), obtida em cada mês de idade, multipli cada pelo número de Rn. Esta estimativa pode ser resumidamente demonstrada na seguinte equação $: \mathrm{FdRn}=\mathrm{XFRc} \times \mathrm{Rn}$.

Portanto o total de fascículos dispersados $(\mathrm{Fd})$ foi considerado como sendo o resul tado da adição dos fascícu los dispersados dos racemos incompletos (FdRi) e de fascículos dispersados dos racemos completos (FdRc ). O total de fascículos produzidos (Fp) foi estimado a partir da adição de Fm ( fascículos maduros ), Fi ( fascículos imaturos) e Fd.

O índice de dispersão (ID) das plan tas de cada população experimental foi conside rado como a relação entre o total de fascícul os dispersados (Fd) e o total de fascículos produzidos (Fp ). O maior ID foi considerado igual a 1,0 e todos os outros calculad os prop orci onal mente a este, resultando os índices de dispersão relativa (IDr). Foram calculados os ID e os IDr, para cada idade, proveniente de todas as semeaduras.

\section{RESULTADOS E DISCUSSÃO}

A duração do ciclo biológico variou de 120 a 210 dias ( fig. 1) e o início do flore scimento ocorreu no período de 60 a 150 dias após a semeadura. As plantas de novembro, dezembro e janeiro floresceram mais precocemente aos 60 dias. As de fevereiro, março, maio e junho floresceram aos 120 dias, as de abril aos 150 dias e as de julho a outubro aos 90 dias. A comparaçã̃o com os dados pluviométricos da época sugere uma correlação entre a pluviosidade durante os três primeiros meses e a data do início do florescimento. Assim, pode-se associar o retardamento da formação das flores pelas plantas de fevereiro a junho, com a pouca pluviosidade desse período. Tenório (14) cita o capim-carrapicho como uma das forrageiras mais procuradas pelos animais do interior de Pernambuco. A baixa pluviosidade da região pode ser a causa provável para o retardamento do florescimento.
O quadro 1 apresenta os totais de fascículos produzidos (Fp) e fascículos dispersados $(\mathrm{Fd})$ e os índices de dispersão (ID ). As plantas obtidas das semeaduras realizadas em fevereiro, março, maio, jun ho e julho ini ciaram a disper são aos 120 dias de idade, as de agosto a janeiro aos 90 dias e as de abril aos 150 dias. A comparação com os dados de temperatura e insolação sugere que estes fatores pos sam ter exe rcido grande in fluên cia sobre a data do início da dispersão. As plantas a partir desse período apresentavam Rc, Ri e Rn.

O quadro 2 apresenta o índice de dispersão (ID) em valores absolutos e os índi ces de dispersão relativos (IDr ), co mo percentuais do mai or índice obtido em dezembro. Estes resultados destacam a importância das condições ambientais, de acordo com o mês de semeadura pa ra o desenvolvimento e crescimento da planta.

O quadro 3 realça a influência da idade e da época de semeadura sobre a produção da planta. Os resultados mostram que é sempre maior a quantidade de fascículos com uma cariopse. O percentual de fascículos com uma cariopse variou de $48 \%$ nas plantas de abril a $90 \%$ aproximadamente nas plantas de março. Com 2 cariopses variou de cerca de $10 \%$ nas plantas de março a cerca de $32 \%$ nas plantas de novembro. Com 3 cariopses variou de zero nas plantas de março a $14 \%$ nas de abril.

Os fascículos maduros apareceram no $2 .^{\circ}$ mês de idade somente nas plant as de novembro e no 3." mês de dezembro, janeiro, setembro e outubro. No $4 .^{\circ}$ mês todas as plantas apresentavam frutos com exc eção das de abril. No $5^{\circ}$ mês, apesar da produção bastante pequena das plantas de fevereiro e março e também, da ausência de plantas de setembro e out tubro, ocorreu a maior produção de Fm, que foi devida às plantas de novembro a agosto e corres pondeu a $27 \%$ do total geral. Entretanto, as plantas de 3 meses de idade provenientes das semeaduras realizadas em novembro, janeiro, agosto, se- 
Quadro 1 - Fascículos produzidos (Fp) e dispersados (Fd) e índice de dispersão (Fp/Fd), por idade e mês de semeadura, por planta.

\begin{tabular}{|c|c|c|c|c|c|c|c|}
\hline \multirow{2}{*}{\multicolumn{2}{|c|}{$\begin{array}{l}\text { Mês } \\
\text { de } \\
\text { semeadura }\end{array}$}} & \multicolumn{6}{|c|}{ idade (em meses) } \\
\hline & & \multirow{2}{*}{$-\frac{2}{44,1}$} & \multirow{2}{*}{$\frac{3}{410,1}$} & \multirow{2}{*}{$\frac{4}{446,9}$} & \multirow{2}{*}{$\begin{array}{r}5 \\
544,8\end{array}$} & \multirow{2}{*}{$\begin{array}{c}6 \\
948,1\end{array}$} & \multirow{2}{*}{$\frac{7}{1083,9}$} \\
\hline Nov & Fp & & & & & & \\
\hline & Fd & 0 & 86,5 & 291,5 & 319,7 & 770,1 & 970,3 \\
\hline & ID & 0 & $21,1 \%$ & $65,2 \%$ & $58,7 \%$ & $81,2 \%$ & $89,4 \%$ \\
\hline \multirow[t]{3}{*}{ Dez } & Fp & 2,0 & 22,5 & 62,4 & 365,1 & 485,0 & 661,9 \\
\hline & Fd & 0 & 3.0 & 11,0 & 211,8 & 399,3 & 607,2 \\
\hline & ID & 0 & $13,3 \%$ & $17,6 \%$ & $58,0 \%$ & $82,3 \%$ & $91,7 \%$ \\
\hline \multirow[t]{3}{*}{ Jan } & Fp & 2,0 & 74,1 & 101,5 & 226,3 & 449,7 & 962,4 \\
\hline & Fd & 0 & 9,5 & 16,9 & 118.2 & 374,2 & 513,4 \\
\hline & ID & 0 & $12,8 \%$ & $16,6 \%$ & $52,2 \%$ & $83,2 \%$ & $53,3 \%$ \\
\hline \multirow[t]{3}{*}{ Fev } & Fp & 0 & 0 & 15,5 & 19,8 & 61,5 & - \\
\hline & $\mathrm{Fd}$ & 0 & 0 & 5,0 & 1,5 & 46,0 & - \\
\hline & ID & 0 & 0 & $32,2 \%$ & $75,7 \%$ & $\mathbf{7 4 , 8} \%$ & - \\
\hline \multirow[t]{3}{*}{ Mar } & Fp & 0 & $\mathbf{0}$ & 24,3 & 26,4 & - & - \\
\hline & $\mathrm{Fd}$ & 0 & 0 & 5,6 & 7,6 & - & - \\
\hline & ID & 0 & 0 & $23,0 \%$ & $28,8 \%$ & - & - \\
\hline \multirow[t]{3}{*}{ Abr } & Fp & 0 & 0 & 0 & 59,2 & 164,0 & 198,0 \\
\hline & Fd & 0 & 0 & 0 & 10,4 & 93,1 & 175,4 \\
\hline & ID & 0 & 0 & 0 & $26,5 \%$ & $56,7 \%$ & $88,6 \%$ \\
\hline \multirow[t]{3}{*}{ Mai } & Fp & 0 & 0 & 20,7 & 62,1 & 92,3 & 92,5 \\
\hline & Fd & 0 & $\mathbf{0}$ & 0,8 & 36,5 & 80,5 & 80,8 \\
\hline & ID & 0 & $\mathbf{0}$ & $3,9 \%$ & $58,8 \%$ & $87,2 \%$ & $87,3 \%$ \\
\hline \multirow[t]{3}{*}{ Jun } & Fp & 0 & 0 & 32,9 & 33,1 & 68,2 & 146,0 \\
\hline & $\mathrm{Fd}$ & 0 & 0 & 5,4 & 15,4 & 27,4 & 125,6 \\
\hline & ID & 0 & 0 & $16,4 \%$ & $46,5 \%$ & $40,2 \%$ & $8,60 \%$ \\
\hline \multirow[t]{3}{*}{ Jul } & Fp & 0 & 2,8 & 41,6 & 242,6 & 338,9 & 342,0 \\
\hline & $\mathrm{Fd}$ & 0 & 0 & 4,3 & 117,0 & 263,4 & 310,8 \\
\hline & ID & 0 & 0 & $10,3 \%$ & $48,2 \%$ & $77,7 \%$ & $90,9 \%$ \\
\hline \multirow[t]{3}{*}{ Ago } & $\mathrm{Fp}$ & 0 & 6,0 & 62,9 & 262,3 & - & - \\
\hline & Fd & 0 & 1,0 & 3,0 & 210,5 & - & - \\
\hline & ID & 0 & $16,6 \%$ & $4,8 \%$ & $80,2 \%$ & - & - \\
\hline \multirow[t]{3}{*}{ Set } & Fp & 0 & 74,2 & 76,0 & - & - & - \\
\hline & Fd & 0 & 16,8 & 34,4 & - & - & - \\
\hline & ID & 0 & $22,6 \%$ & $45,3 \%$ & - & - & - \\
\hline \multirow[t]{3}{*}{ Out } & Fp & 0 & 72,7 & 123,0 & - & - & - \\
\hline & Fd & 0 & 23,0 & 62,7 & - & - & - \\
\hline & ID & 0 & $31,2 \%$ & $51,0 \%$ & - & - & - \\
\hline
\end{tabular}




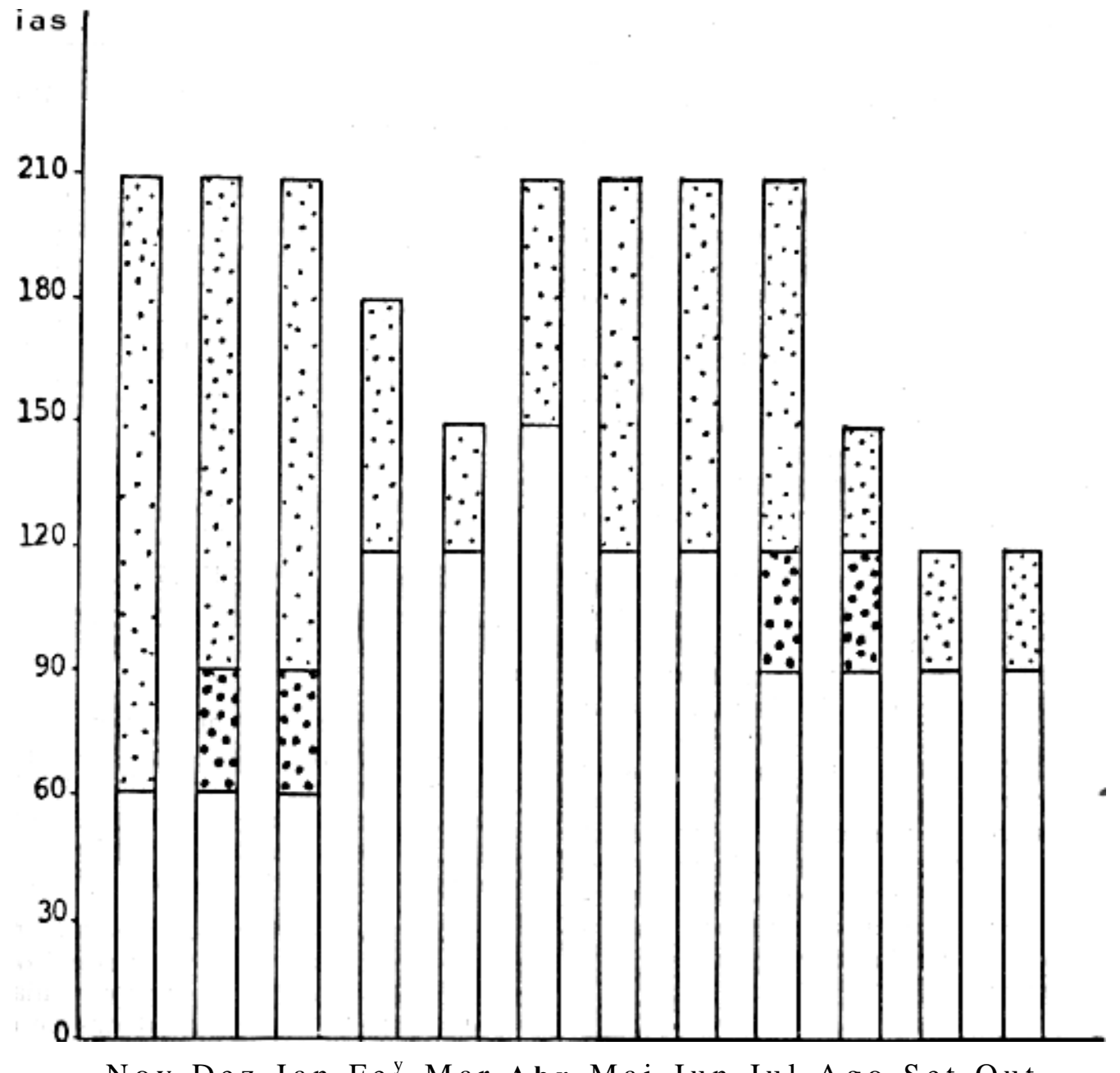

Nov Dez Jan Fe Mar Abr Mai Jun Jul Ago Set Out

Figura I. Duração do ciclo biológico (ordenada) das plantas de semeaduras realizadas de novembro a outubro (abscissa).

果

Periodo com flores e sem frutos

Período com flores e frutos. 
tem bro e out ubro aprese ntara m produ ção considerável de Fm. As plantas de novembro se destacaram pela produção, que representou $70 \%$ do total produzido nessa idade.

Considerando as quantidades de racemos, de fascículos e de cariopses, a época de florescimento, duração de dispersão do ciclo de vida pode-se caracterizar 4 períodos de semeadura (quadro 4). As plantas de novembro, dezembro e janeiro (1." período) tiveram o florescimento mais precoce aos 2 meses de idade, dispersaram fascículos durante 120 dias e o ciclo durou 210 dias (cerca de 7 meses). Das 210 plantas coletadas neste período, 180 apresentaram em média 10 a 27 race-mos por planta, perfazendo $73 \%$ do total geral e com cerca de 23 fascículos por racemo e cerca de 360 fascículos em média por planta, perfazendo $70 \%$ do total geral. As plantas de fevereiro e março (2." período) começaram a florescer no 4." mês de idade, dispersaram fascículos durante 60 dias e o ciclo de vida durou 150 e 180 dias ( março e fevereiro, respectivamente ). Das 110 plantas coletadas (60 de fevereiro e 50 de março) somente 50 apresentaram em média, menos de 2 racemos por planta, perfazendo cerca de $2^{\circ} \%$ o do total geral, com cerca de 21 fascículos por racemo e 29 fascículos por planta, igualmente perfazendo, cerca de $2 \%$ do total geral.

A relação de fascículos por race mo foi no segundo período, muito semelhante à do primeiro período. Isto significa que os racemos não diferiram na composição mas sim, na quantidade total de racemos.

As plantas nascidas no primeiro período produziram aproximadamente doze vezes mais racemos, result ando treze vezes mais fascículos que nas plantas nascidas no segundo período. As plantas do terceiro período ( abril a julho) iniciaram o florescimento no $4 .^{\circ}$ mês (as de abril no 5."), dispersaram fascículos durante 60 dias (as de abril) e 90 dias (as de maio, junho e julho) ; o ciclo de vida durou cerca de 210 dias. Das 280 plantas
Quadro 2 - Índice de dispersão absoluto (ID) e relativo (IDR) de plantas de diferentes meses de semeadura.

\begin{tabular}{crr}
\hline $\begin{array}{c}\text { Mès de } \\
\text { semeadura }\end{array}$ & ID & \multicolumn{1}{c}{ IDR } \\
\hline Nov & $70,0 \%$ & $90,9 \%$ \\
Dez & $77,0 \%$ & $100,0 \%$ \\
Jan & $57,8 \%$ & $75,1 \%$ \\
Fev & $22,2 \%$ & $28,8 \%$ \\
Mar & $24,8 \%$ & $32,2 \%$ \\
Abr & $69,4 \%$ & $90,1 \%$ \\
Mai & $74,3 \%$ & $96,5 \%$ \\
Jun & $62,0 \%$ & $80,5 \%$ \\
Jul & $55,7 \%$ & $72,3 \%$ \\
Ago & $64,8 \%$ & $84,2 \%$ \\
Set & $34,1 \%$ & $44,3 \%$ \\
Out & $43,8 \%$ & $56,9 \%$ \\
\hline
\end{tabular}

coletadas (70 de cada população), 150 apresentaram em média 5 racemos por planta, perfazendo cerca de $19 \%$ ido total geral, com cerca de 25 fascículos por racemo e cerca de 128 fascículos por planta, perfazendo $21 \%$ do total geral.

A relação das quantidades de racemo e de fas cículos entre os primeiro e terceiro períodos foi de aproximadam ente 3 e a rela ção das quan tidades de cariopses foi igual a 2,4. A relação das quantidades de fascículos entre os primeiro e terceiro períodos foi igual a quatro.

As plan tas do quarto perío do (agos to a outubro) iniciaram o flor esciment o no 3. ${ }^{\circ}$ mês, dispersaram fascículos durante 60 dias (as de agosto) e 90 dias (as de setembro e outubro) e 150 dias (agosto). Das 130 plantas coletadas (50 de agosto, 40 de setembro e 40 de outubro ), 70 apresentaram em média 4 racemos por planta, perfazendo $7 \%$ do total geral, 25 fascículos por racemo e cerca de 97 fascículos por planta, perfazen do cerca de $7 \%$ do total geral. A relação das quantidades de racemos e fascículos entre o primeiro e quarto períodos foi aproximadamente 
Quadro 3 - Produçăo de fascículos maduros com 1, 2, 3, 4 e 5 cariopses, por idade e por mês de semeadura.

\begin{tabular}{|c|c|c|c|c|c|c|c|c|c|c|c|c|c|c|c|c|c|c|c|c|c|c|c|c|c|c|c|c|c|c|}
\hline \multirow{2}{*}{$\begin{array}{l}\text { Mês } \\
\text { de } \\
\text { semeadura }\end{array}$} & \multicolumn{5}{|c|}{2 meses } & \multicolumn{5}{|c|}{3 meses } & \multicolumn{5}{|c|}{4 meses } & \multicolumn{5}{|c|}{5 meses } & \multicolumn{5}{|c|}{6 meses } & \multicolumn{5}{|c|}{7 meses } \\
\hline & 1 & 2 & 3 & 4 & 5 & 1 & 2 & 3 & 4 & 5 & 1 & 2 & 3 & 4 & 5 & 1 & 2 & 3 & 4 & 5 & 1 & 2 & 3 & 4 & 5 & 1 & 2 & 3 & 4 & 5 \\
\hline Nov & 21 & 15 & 8 & 2 & 0 & 1254 & 727 & 233 & 47 & 9 & 174 & 119 & 14 & 0 & 0 & 735 & 405 & 107 & 26 & 2 & 533 & 247 & 103 & 17 & 3 & 213 & 118 & 32 & 1 & 0 \\
\hline Dez & 0 & 0 & 0 & 0 & 0 & 6 & 0 & 0 & 0 & 0 & 178 & 112 & 33 & 13 & 0 & 433 & 119 & 21 & 3 & 0 & 189 & 38 & 4 & 0 & 0 & 123 & 49 & 22 & 8 & 0 \\
\hline Jan & 0 & 0 & 0 & 0 & 0 & 195 & 97 & 48 & 8 & 2 & 54 & 38 & 4 & 5 & 0 & 237 & 119 & 39 & 8 & 2 & 197 & 114 & 40 & 7 & 0 & 136 & 70 & 8 & 1 & 0 \\
\hline Fev & 0 & 0 & 0 & 0 & 0 & 0 & 0 & 0 & 0 & 0 & 15 & 6 & 1 & 0 & 0 & 8 & 0 & 0 & 0 & 0 & 25 & 5 & 0 & 0 & 0 & - & - & - & - & - \\
\hline Mar & 0 & 0 & 0 & 0 & 0 & 0 & 0 & 0 & 0 & 0 & 21 & 7 & 0 & 0 & 0 & 63 & 2 & 0 & 0 & 0 & - & - & - & - & - & - & - & - & - & - \\
\hline Abr & 0 & 0 & 0 & 0 & 0 & 0 & 0 & 0 & 0 & 0 & 0 & 0 & 0 & 0 & 0 & 40 & 18 & 5 & 5 & 0 & 207 & 162 & 75 & 10 & 1 & 96 & 69 & 19 & 1 & 0 \\
\hline Mai & 0 & 0 & 0 & 0 & 0 & 0 & 0 & 0 & 0 & 0 & 35 & 0 & 0 & 0 & 0 & 41 & 10 & 6 & 2 & 0 & 28 & 14 & 2 & 1 & 0 & 56 & 8 & 0 & 0 & 0 \\
\hline Jun & 0 & 0 & 0 & 0 & 0 & 0 & 0 & 0 & 0 & 0 & 38 & 9 & 1 & 0 & 0 & 56 & 28 & 6 & 1 & 2 & 120 & 38 & 20 & 8 & 5 & 73 & 45 & 9 & 3 & 0 \\
\hline Jul & 0 & 0 & 0 & 0 & 0 & 0 & 0 & 0 & 0 & 0 & 113 & 56 & 21 & 1 & 0 & 344 & 119 & 20 & 4 & 0 & 248 & 127 & 38 & 2 & 0 & 83 & 60 & 18 & 7 & 0 \\
\hline Ago & 0 & 0 & 0 & 0 & 0 & 10 & 0 & 0 & 0 & 0 & 56 & 0 & 0 & 0 & 0 & 145 & 48 & 23 & 2 & - & - & - & - & - & - & - & - & - & - & - \\
\hline Set & 0 & 0 & 0 & 0 & 0 & 262 & 88 & 22 & 2 & 0 & 159 & 56 & 22 & 5 & 0 & - & - & - & - & - & - & - & - & - & - & - & - & - & - & 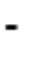 \\
\hline Out & 0 & 0 & 0 & 0 & 0 & 124 & 87 & 23 & 3 & 0 & 182 & 89 & 30 & 5 & 2 & - & - & - & - & - & - & - & - & - & - & - & - & - & - & - \\
\hline
\end{tabular}




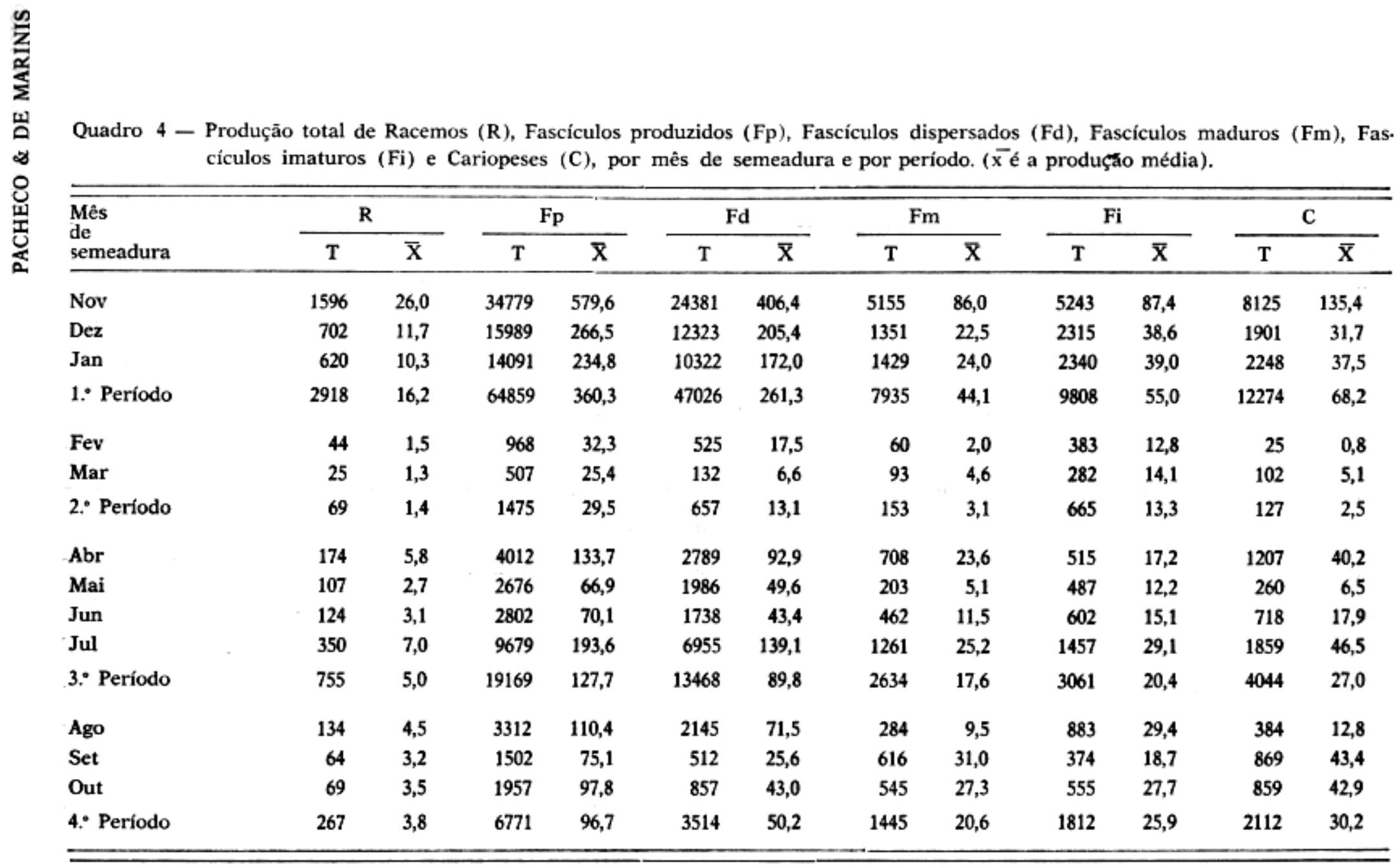


igual a 4 e a relação da quantidade de fascículos remanescentes foi cerca de 2 . Portanto, os resultados mostraram que as plantas de novembro, dezembro e janeiro (1. ${ }^{0}$ período) diferiram de todas as outras quanto à capacidade reprodutiva, representada pela grande produção de racemos (70\% do total geral), que foi doze vezes maior que a do segundo período, cerca de três vezes maior que a do terceiro período e quatro vezes maior que a do quarto período. As plantas do terceiro e quarto períodos apresentaram-se semelhantes entre si nas relações de quantidades de racemos, de fascículos e de cariopses (aproximadamente igual a 1,0). As plantas do terceiro período apresentaram maior ID que as do quarto período. As do segundo período diferiram das demais pela pequena capacidade reprodutiva e menor ID.

Relacionando -se os dados obtidos para as populações experimentais com aqueles obtidos para a população natural (12), pode-se supor que as plantas coletadas da natureza no período de janeiro a março, (o de maior quantidade de elementos reprodutivos) provavelmente representariam aquelas que iniciaram o desenvolvimento desde agosto (que em janeiro estariam no $5^{\circ}$ mês e em março no $7^{\circ}$ mês) até aquelas de novembro (que em janeiro estariam no $2^{\circ}$ mês e em março no $4^{\circ}$ mês). Portanto, pode-se sugerir que em uma programação de controle será importante evitar-se o armazenamento de fascículos dispersados, principalmente de julho a outubro, impedindo-se desse modo a germinação durante o período mais chuvoso, das plantas mais vigorosas e de maior produtividade (as de novembro a janeiro).

\section{AGRADECIMENTOS}

Pela leitura crítica do manuscrito os nossos melhores agradecimentos ao Dr. Robinson Antonio Pitelli e à Dra. Eurides Mambreu de Menezes. Ao Dr. James Robert Coleman pela versão em inglês do resumo.

\section{LITERATURA CITADA}

1. Arévalo, R.A. \& Camargo, P.N. O controle das principais invasoras da cana. A Gran. ja, 36(393): 46-59, 1980.

2. Blanco, H.G. Catálogo de mato infestante de áreas cultivadas no Brasil - Gramíneas de ciclo anual. $O$ Biológico, 41: 6-14, 1975.

3. Coleman, M.T.A. Levantamento botânico da flora de pastagens da regiåo nordeste do Estado de São Paulo. Vegetalia, 10: 1-14, 1980.

4. Dedecca, D.M. Plantas invasoras de cafezais. Agricultura Pec., 30(432): 40-42, 1959.

5. Deuber, R., Forster, R. \& Signori, L.H. Efeitos de herbicidas na anatomia de capimcarrapicho e amendoim-bravo. Bragantia, 36(20): 207-213, 1977.

6. De Marinis, G. Plantas agrófilas da região de São José do Rio Preto, Estado de São Paulo. In: Sem. Bras. Herm. Ervas Dan. 6. Sete Lagoas, 1966. An. p. 31-41, 1968.

7. Felippe, G.M.; Silva, J.C.S. \& Ribeiro, J.F. Estudo da influência da qualidade de luz na germinação de ervas invasoras em condiçóes controladas. Ci e Cul., 29(7): 561. 562. (Supl.), 1977.

8. Holm, L.R.G., Pluconett, D.L. \& Pancho, S.V. The World's Worst weeds distribution and biology. Honolulu. The University Press of Hawaii. XII - 609 p., 1977.

9. Leitão Filho, H.F., Aranha, C. \& Bacchi, O. Plantas invasoras de culturas no Estado de São Paulo. São Paulo. HUCITEC, vol. I, 296 p., 1972.

10. Pacheco, R.P. de B. \& De Marinis, G. Primeira nota sobre a capacidade reprodutiva do capim-carrapicho (Cenchrus echt. natus L.). Bol. Fac. Fil. Ciên. Letras Presi. dente Prudente, 1: 71-76, 1974.

11. Pacheco, R.P. de B. \& De Marinis, G. Primeiras investigaçōes de Malerbecologia na Região Sudoeste do Estado de Săo Paulo, Brasil. III Congr. Assoc. Latinoamericano de Malezas. Mar del Plata, Trabajos y Resumenes, 67-72, 1976.

12. Pacheco, R.P. de B. Crescimento vegetativo e capacidade reprodutiva de Cenchrus echinatus $\mathrm{L}_{\text {, }}$ na regiāo Sudoeste do Estado de Sāo Paulo. Dissertação. Instituto de Biociências - Rio Claro, UNESP, 1981.

13. Soares, A.A. Estudo preliminar da distribuição geográfica e por cultura das principais plantas daninhas do Estado de Săo Paulo. (Trabalho de Graduação em Agronomia). Fac. Med. Vet. Agron. UNESP, Jaboticabal, S.P., 58 p., 1976.

14. Tenório, E.C. $O$ gênero Cenchrus no Nordeste. An. Inst. Biolog. U.F. Pe. 1(1): 83-95, 1971. 